\title{
Hmong Needlework: Development of Interior Decoration Patterns and Products for a Creative Economy
}

\author{
Thongchue Khiatthong ${ }^{1}$, Kla Somtrakool ${ }^{1} \&$ Pirat Tidpard $^{1}$ \\ ${ }^{1}$ The Faculty of Cultural Science, Mahasarakham University, Khamriang Sub-District, Kantarawichai District, \\ Maha Sarakham, Thailand \\ Correspondence: Thongchue Khiatthong, Dhonburi Rajabhat Universty, 172 Isaraphap Rpad, Thonburi, Bangkok \\ 10600, Thailand. E-mail: thongchue@gmail.com
}

Received: May 28, 2013 Accepted: July 2, 2013 Online Published: September 29, 2013

doi:10.5539/ass.v9n13p196 URL: http://dx.doi.org/10.5539/ass.v9n13p196

\begin{abstract}
This research examines the inherited embroidery techniques of the Hmong ethnic group in Northern Thailand. This intricate and valuable handicraft is used to create garments for traditional ceremonies and rituals but its general reputation for the creation of everyday items is on the wane in the face of more popular global fashions. This study investigates the possibility of creating a larger variety of product development for use in interior housing decoration, such as curtains, pillow-cases and place-mats. The researchers conclude that, with the correct development of products, systematic collection of design models and simpler needlework techniques for inheritance, Hmong embroidery can battle the Western styles for a place in the everyday life of the consumer and generate a higher earning potential for the ethnic community.
\end{abstract}

Keywords: Hmong, needlework, embroidery, development, product, patterns, decoration, creative economy

\section{Introduction}

Needlework of hill-tribe people is a handicraft that has been inherited from ancestors for hundreds of years. The craft was developed during free-time among females after work in the fields had finished. Cotton planted in the village was spun into fine threads and woven into reams. These reams were then designed with ancient tribal patterns. The handicraft was developed according to the satisfaction of the people and became a hill-tribe production with important mental value. Hill-tribe embroidery is an indigenous craft that is visible in every hill-tribe settlement and uses beautiful designs that occur from thorough and delicate handiwork. This generates a special interest in hill-tribe needlework, whether it is used for clothing or household objects. Hmong people have an artistic culture of creative clothing decoration (ornamentation) that is no less prominent than other tribal communities and is particularly visible in clothing embroidery, which is their highest value artistic handicraft.

Clothing of the Northern ethnic groups in the past was woven and sewn within the group, instilling valuable pride in the products. However, nowadays ethnic groups prefer mass-produced clothing that is cheap, easy to find, easy to wear, suitable for hotter climates and makes the wearer conform to the tastes of the majority of the nation. Today, youth are sent to nurseries from the age of two years old and from here graduate to schools. This reduces the opportunity to inherit the local wisdom of the ancestors because when they return home they turn on the television to watch national shows or global satellite channels. The new generations watch television concerning modern society and the future. There is therefore a lack of efficient inheritance of pride in ancestry and history (Deethet, 2009, p.14-15).

From studies in economic, social and cultural adaptation of the Hmong people under the development program of Poppra Sub-district, Tak province, it was found that the absorption of culture by the community from the city caused alteration of existing culture and customs. This transformed the lifestyle of Hmong people from its original social condition to that of a new society by both developing existing customs and causing others to disappear (Jaroenpalitpon, 2001, p.140-46). Nevertheless, there is market demand for modern Hmong needlework that uses old styles to create a variety of products but it does not offer as much income as it should.

Every government places importance on the conservation of culture and is able to generate additional income from local cultural products in order to distribute among the community by defining a continuous development plan. This is similar to point 5.2 (2) of the tenth National Economic and Social Development Plan, strategy for 
the creation of community and social strength that is a foundation of national solidarity. This places importance on the creation of economic stability in the community by integrating potential production and balanced community strength. The emphasis is on sufficient production for community consumption sponsored by the creation of social cooperative groups in the community. Occupation groups are also created and supported by the use of local wisdom and local culture in the creation of material and management value (Office of the National Economic and Social Development Council, 2006). Aside from this, the tenth National Economic and Social Development Plan stipulates that the strengthening, balancing and creation of production in industry and tourism puts emphasis on a creative economy, which includes creative business development, creative city development and creative industrial development (Office of the National Economic and Social Development Council, 2011, p.17-25). These are all comprised of modern government with programs that involve economy based on the foundations of knowledge and education. The creation of results and the use of intellectual property that is connected to cultural roots are compatible with the accumulation of social and technological knowledge, as well as modern innovations or 'creative economy'. The importance of this is when the market is full of similar goods and services that have been mass-produced by modern machinery. People do not have a need for the excess produce and the modern global markets do not satisfy the physical needs of the consumer. There must be variety to match the different moods, interests, values and social statuses of the people. Cultural heritage and the media have the highest value in strengthening the Thai nation and developing its ability to compete with foreign powers. The reason for this is Thai human resources; people who are creative and skilled at art and artistic traditions (Laisatruklai, 2009, p.107-115). Lifestyle, wisdom and cultural heritage are high-value resources to Thailand that can propel the economy. As well as using these resources for creativity and development to increase value, they may be used to benefit commerce and the national economy.

From these facts, it can be concluded that Hmong people are an ethnic group that have cultural foundations and a unique identity. The biggest expression of their identity is needlework and embroidery, which, despite its beauty and interest, is decreasing in importance due to social changes. Its importance only remains in the New Year's festival of the Hmong people. The development of Hmong needlework is occasionally used to create other products but it does not command the market value that it should. The development of Hmong needlework in accordance with the government strategies of creative economy has not been studied with regards its cause and importance. This was the reason for the researchers' interest in studying the production of Hmong embroidery products that are based on original ideas and local wisdom and integrate new concepts. This especially includes development of patterns, colors and uses of interior decoration products so that they correspond to consumer requirements and ultimately increase the economic value of production.

\section{Research Aims}

This research had three primary aims: a) to study the historical background of Hmong communities and local wisdom of Hmong needlework designs; b) to study the current problems and development method for Hmong needlework products for a creative economy; c) to develop interior decoration patterns and products from Hmong needlework for a creative economy.

\section{Research Methodology}

The research area included Ban Doi Nam Pieng Din, Ban Noen Sub-District, Lom Kao District, Ban Lao Leu Ban Lao Neng and Ban Kek Noi, Khao Kho Sub-District, Khao Kho District in Phetchabun Province and Ban Mung Mai, Mae Tho Sub-District, Mueang Tak District, Ban Jedi Koh, Mahawan Sub-District, Mae Sot District and Ban Sapanan, Chong Khaep Sub-District, Phop Phra District in Tak Province.

The researcher used a qualitative research method with one hundred and one informants, consisting of twenty-five key informants, fifty-six casual informants and twenty general informants. The research tools used were survey, observation, interview, focus group discussion and workshop. The data was validated using a triangulation method and was analyzed and presented using a descriptive analysis.

\section{Results}

\subsection{The Historical Background of Hmong Communities and Local Wisdom of Hmong Needlework Designs}

The Hmong residents of Tak Province moved into the province over ninety years ago from a number of neighboring Thai provinces, including Nan, Chiang Rai and Phetchabun Provinces. Over time, the groups spread across Tak from their original district to adjoining districts in order to find suitable land to grow food and as part of government relocation schemes. This meant that current Hmong residences are scattered throughout the province. Tak is now home to the largest Hmong population in Thailand.

The Hmong residents in Phetchabun emigrated from Laos over seventy years ago though Nan Province in the 
North of the country. The original immigrants came to Thailand on foot over the border mountains or occasionally by train from Chiang Rai via Phitsanulok and on foot via Phichit to Phetchabun. The first settlements were in Ban Kek Noi Gao, Lom Sak District. From here, the Hmong people eventually moved into other provinces, such as Tak, and other districts within Phetchabun because of Thai governmental problems with the threat of communism. Once the initial problems had been overcome, the Hmong people were able to establish and strengthen their own communities in two districts of Phetchabun, Lom Kao and Khao Kho. The Hmong community at Ban Kek Noi, Khao Kho Sub-District, Khao Kho District is the largest community in Thailand.

From research into the designs of Hmong needlework, it was discovered that the patterns used are part of the ethnic identity inherited from Hmong ancestors. The lifestyle of Hmong people is in harmony with nature, the sky, the forest and the rivers. These features are clearly visible in the variety of Hmong embroidery designs. It is possible to categorize these patterns into two large groups: ancient and modern. The ancient designs consist of elephant footprints (geudechau), shells (gageu), stars (nugu), money (pangjoo), rat's feet (naengna), shaking hands (patuate), mountains (jong), chicken heads (taohaoka), saw-tooth patterns (neeyagley) and cows' eyes (kawmua-ngu). The modern patterns have been developed and designed to meet individual consumer needs and include hearts ( $s a$ ), peacocks, butterflies (pongpai), floral designs (pang), garlands (pangjao), ferns (plangsua), chickens (gai), dogs (day) and various Hmong lifestyle scenes. Females in the Hmong ethnic group have inherited the methods of Hmong embroidery from teaching within the family from one generation to the next. The embroidery is necessary for making tribal clothing and for use in various ceremonies, such as weddings, funerals and particularly during the Hmong New Year's ceremony. Hmong people have a number of methods for embroidering their designs onto the fabric, which include six basic embroidery stitches: outline stitch; cross-stitch; stitching in plus-sign patterns; chain stitch; satin stitch; appliqué to showcase Hmong lifestyle. The appliqué styles used are to affix geometric shapes, pre-patterned fabrics and mixed technique, including batik appliqué, embroidery of materials and mixture of all the aforementioned techniques. The materials required for Hmong needlework are needles of different sizes, cotton thread, different colored fabrics, hemp or cross-stitch fabric, scissors, stencils, designs and sewing machinery.

\subsection{The Current Problems and Development Method for Hmong Needlework Products for a Creative Economy}

The majority of Hmong people with skill in embroidery are elderly and there is a lack of people to inherit the wisdom of Hmong needlework because the younger females undertake higher and further education. There is also a greater attraction to occupations with higher earning potential. There is no development of new styles and the colors used in embroidery depend on the individual designers, who do not consider consumer demand. There is no collection of ancient Hmong needlework styles to use as examples for Hmong needlework products. The current products are tribal clothing for the community. There is some production of bags, telephone cases and pillow cases as souvenirs but these products cannot increase the earning potential from Hmong embroidery.

There should be a collection of Hmong embroidery designs as examples and the designs should be developed so that they are easier for the new generations to create. The products must also meet the requirements of the market. There must be design and development of new products that can increase the value of Hmong embroidery. There must be a variety of product examples to meet consumer needs and increase the community production and trade. There should be study to identify the color preferences of the market in order to develop the selection of colors to correspond to consumer needs. However, the products must remain based on the local wisdom of the Hmong people so that the embroidery continues to have value in the future.

\subsection{Development of Interior Decoration Patterns and Products from Hmong Needlework for a Creative Economy}

The development of patterns uses theories of aesthetics according to the following artistic components: a) shapes of Hmong needlework patterns should be defined to suitably correspond to the form and use of the product as well as the size of the item; $b$ ) the spacing and frequency of patterns should be defined so that they are equal and symmetrical with intervals that make the design look modern and beautiful, while remaining based on the foundations of Hmong identity; c) threads should be used that are suitable for the design and fabric, along with colors that match, so as to create seamless joints in the product; d) the colors and patterns must not conflict; e) patterns, pattern sizes and colors should be defined in order to make the product stand out and attract customers.

The researchers used Wibun Leesuwan's method of design for products made in accordance with local wisdom. Styles of old and new products are developed that are appropriate for modern lifestyles. The products are developed for use in interior decoration of buildings and offices. The products include tapestries, table lamps, floor lamps, curtains, place-mats, pillow-cases and bed sheets. The materials used in productions should be 
natural resources or synthetic materials that are suitable for the product. The styles of the Hmong embroidery should be chosen for their link to Hmong identity and appropriateness for the product. Emphasis must be placed on conditions of mental beauty and the suitability of using appliqués. A target group for purchase of products should be identified and should include adults and administration officials, hotel businesses and middle-sized spas. The product design process must include creative participation from members of these groups.

\section{Discussion}

\subsection{The Historical Background of Hmong Communities and Local Wisdom of Hmong Needlework Designs}

The Hmong people emigrated south from China through Laos in order to settle in Thailand. This agrees to the research of Prasit Leepreecha (2008, p.121), which found that Hmong emigration from China into the North of Thailand occurred during the twentieth century. The Hmong ethnic group first came to Tak Province over eighty years ago and, from these origins, moved around to the mountainous areas in Northern Thailand. The Hmong population in Tak Province is the largest in Thailand.

The patterns and designs of Hmong needlework have been inherited from ancestors and reflect the identity of the Hmong ethnic group. The Hmong people live in harmony with nature, the sky, mountains and rivers and this is visible in the designs of the embroidery. This corresponds to the findings of Chanthasone Inthavong (2001, p.70), which stated that the creation of Hmong needlework came from the nature surrounding the community, such as flowers, shells, fish-scales, vines, rocks, elephants, cauliflower, heartwood, various seeds, grasses, peacock eyes, chicken eyes, centipedes and caterpillars. The patterns can be divided into two major categories: old and new. This relates to the research of Kaisree Jitsamran (2006, p.91-144), which found that the majority of Hmong embroidery patterns were influenced by natural surroundings and religious beliefs related to everyday life. These generated a Hmong identity that has been inherited over time and has become the traditions and cultures that are practiced today. In Ban Kek Noi, Petchabun Province, patterns in the first category of designs number forty-nine and the total of developed patterns in the second category is one-hundred and thirty-one. Each design is related to the folk wisdom and identity of Hmong people. This confirms the research of Ampai Teeronnasan (2012), which discussed the theories of aesthetics. According to Teeronnasan, there are two aesthetic theories: mimetic theory and diegesis. The research particularly concerns memesis, which Teeronnasan describes as placing particular importance on the universe or nature. Consideration of the value of art under this theory involves the investigation of similarity or likeness to the model in nature or lifestyle. For this reason, the method of artistic creation according to mimetic theory is the imitation of reality as accurately as possible.

The various methods for Hmong embroidery identified by this research fall in line with the findings of Inthavong (2001, p.70), which stated that Hmong techniques stem from four original methods, which are: a) needlework on fabric sheets with holes for threading silk in cross-stitch, line, dot and chain patterns; $b$ ) appliqué of small pieces of fabric on larger sheets according to designs; c) sewing of long fabric strips according to guidelines on larger fabric sheets; d) new designs based on the everyday lifestyle of Hmong people.

\subsection{The Current Problems and Development Method for Hmong Needlework Products for a Creative Economy}

The problems found with Hmong embroidery correspond to the work of Prasert Trakarnsupakorn (1999), which concerned the craftwork of five tribal groups. The results found that Mien needlework focused on the creation of a lasting ethnic identity for the Mien community in Chiang Rai Province. The prominent features of the patterns were concerned with history, legends and beliefs of needlework patterns, styles, knowledge and techniques. The beliefs and meanings associated with embroidery related to the lifestyle of Mien people provide an insight into modern social changes. The results of these changes were found to affect the economy of Mien needlework.

Local wisdom should create awareness of the value of Hmong embroidery by developing products to increase the earning potential from the handicraft. There should be a collection of designs that can be used as a reference for easy product creation and development. Consumer requirements should also be studied and new product developments should meet these needs, while also retaining the original identity. These thoughts agree with the studies of Akin Raphipat (2008, p.122), which compared humanity to a spider, weaving a web of culture. The study of this culture is thus the search for and the assignment of meaning rather than any specific scientific experimentation to identify a set of rules.

\subsection{Development of Interior Decoration Patterns and Products from Hmong Needlework for a Creative Economy}

Results concerning the artistic components of Hmong embroidery are consistent with the research of Chujai Kinoo (2007, p.21). Kinoo studied the development of Hmong needlework products in Ban Kek Noi and concluded that the patterns were based on the original Hmong jaidao and laihao designs and incorporated other 
Northern designs from Mae Jaem District in Chiang Mai Province, including an eight-point asterisk and 'bird-cage' patterns. There should be development of designs to combine other old designs and integrate new colors that are popular with tourists to increase the attractiveness of the products, without losing the original identity.

The development of interior decoration products was conducted using Wibun Leesuwan's method of design for products made in accordance with local wisdom. Katatong Tongyai $(2012, p .1)$ found that designs were aimed at addressing consumer demand because of the normal behavior patterns of humans that sees the formation of groups. However, each individual prefers different designs based on their own tastes and industrial products are limited, so in businesses with high levels of competition, the individual tastes of the consumer should be met. This should be achieved through the cooperation of the consumer in the design process so as to determine what these needs are. For products that create a group of users, there will be greater opportunity to create a higher level of variety. The new products must be accepted by the consumers in line with the principles of Krissaman Wattananarong (2003, p.7). According to Wattananarong, the main factors for consumers accepting new products are higher quality, cheaper cost, new intricacies and relative advantage, which correspond to findings in psychology that suggest people prefer new things. Other causes include social compatibility, relative complexity, 'trialability' and 'observability'. The design of new and beautiful products is related to the research of Songkoon Chantachon (2010, p.88-89). The research concludes impression management can be used in everyday life by manufacturers in order to publicize their ability and trustworthiness.

\section{References}

Chantachon, S. (2010). Theories of culture and society. Maha Sarakham: Mahasarakham University.

Deethet, D. (Kunchon Na Ayutthaya) (2009). The development of ethnic groups in the North: Problems and ways to solve them. Bangkok: Ministry of Culture.

Inthavong, C. (2001). The Faascinating Embroidery Motifs on the Old Cloth of Hmong People. In Legends in the Weaving. The Japan Foundation Asia Center.

Jaroenpalitpon, B. (2001). Study of economic, social and cultural adaptation of Hmong people under the development program of the government in Phop Phra, Tak Province. Bangkok: Mahidol University Press.

Jitsamran, K. (2006). Study of historical background and beliefs in needlework patterns of the Hmong ethnic group in Ban Kek Noi, Kek Noi District, Petchabun Province. Phitsanulok: Naresuan University.

Kinoo, C. (2007). Development of Hmong fabric products in Ban Kek Noi, Kao Kaw District, Phetchabun Province. Bangkok: Chulalongkorn University Press.

Laisatruklai, A. (2009). Creative ideas to propel the economy. Bangkok: TCDC.

Leepreecha, P. (2008). Commerce, land and identity of Hmong Doy Bui under the authority, territory and identity of national lineage. In Cultural politics of the government for Thai society. Bangkok.

Office of the National Economic and Social Development Council. (2006). The tenth national economic and social development plan. Bangkok.

Office of the National Economic and Social Development Council. (2011, December). Ratchakitcha (No. 128, special edition 152).

Raphipat, A. (2008). Culture is the Meaning of Theory and Method of Clifford Gear. Bangkok: Sirinthorn Department of Humanities.

Teeronnasan, A. (2012). Theories of Teaching Art. Bangkok: Chulalongkorn University.

Tongyai, K. (2012, April). Editorial. In Design Vision.

Trakarnsupakorn, P. (1999). Development of community potential among hill-tribes with cultural capital in order to strengthen the economy and society. Retrieved January 5, 2010, from $\mathrm{http}: / /$ www.culture.go.th/research/north/42_5.html

Wattananarong, K. (2003). Lecture documents on the theory of promoting modernization. Maha Sarakham: Mahasarakham University.

\section{Copyrights}

Copyright for this article is retained by the author(s), with first publication rights granted to the journal.

This is an open-access article distributed under the terms and conditions of the Creative Commons Attribution license (http://creativecommons.org/licenses/by/3.0/). 